\title{
Pharmacological Profile of the Novel Antiepileptic Drug Candidate Padsevonil: Characterization in Rodent Seizure and Epilepsy Models
}

\author{
Karine Leclercq, (D)Ain Matagne, Laurent Provins, Henrik Klitgaard, and Rafal M. Kaminski ${ }^{1}$ \\ UCB Pharma, Neurosciences Therapeutic Area, Braine l'Alleud, Belgium
}

Received July 10, 2019; accepted October 10, 2019

\begin{abstract}
The antiepileptic drug (AED) candidate, (4R)-4-(2-chloro-2,2-difluoroethyl)-1-\{[2-(methoxymethyl)-6-(trifluoromethyl)imidazo[2,1b] $[1,3,4]$ thiadiazol-5-yl]methyl\}pyrrolidin-2-one (padsevonil), is the first in a novel class of drugs that bind to synaptic vesicle protein 2 (SV2) proteins and the $\mathrm{GABA}_{\mathrm{A}}$ receptor benzodiazepine site, allowing for pre- and postsynaptic activity, respectively. In acute seizure models, padsevonil provided potent, dose-dependent protection against seizures induced by administration of pilocarpine or 11-deoxycortisol, and those induced acoustically or through $6 \mathrm{~Hz}$ stimulation; it was less potent in the pentylenetetrazol, bicuculline, and maximal electroshock models. Padsevonil displayed dosedependent protective effects in chronic epilepsy models, including the intrahippocampal kainate and Genetic Absence Epilepsy Rats from Strasbourg models, which represent human mesial temporal lobe and absence epilepsy, respectively. In the amygdala kindling model, which is predictive of efficacy against focal to bilateral tonic-clonic seizures, padsevonil provided significant protection in kindled rodents; in mice specifically, it was the most potent AED compared with nine others with different mechanisms of action. Its therapeutic index was also the highest, potentially translating into a favorable efficacy and tolerability profile in humans. Importantly, in contrast to diazepam, tolerance to padsevonil's
\end{abstract}

antiseizure effects was not observed in the pentylenetetrazolinduced clonic seizure threshold test. Further results in the $6 \mathrm{~Hz}$ model showed that padsevonil provided significantly greater protection than the combination of diazepam with either 2S-(2-oxo-1-pyrrolidinyl)butanamide (levetiracetam) or 2S-2-[(4R)-2-oxo-4-propylpyrrolidin-1-yl] butanamide (brivaracetam), both selective SV2A ligands. This observation suggests that padsevonil's unique mechanism of action confers antiseizure properties beyond the combination of compounds targeting SV2A and the benzodiazepine site. Overall, padsevonil displayed robust efficacy across validated seizure and epilepsy models, including those considered to represent drug-resistant epilepsy.

\section{SIGNIFICANCE STATEMENT}

Padsevonil, a first-in-class antiepileptic drug candidate, targets SV2 proteins and the benzodiazepine site of $\mathrm{GABA}_{A}$ receptors. It demonstrated robust efficacy across a broad range of rodent seizure and epilepsy models, several representing drug-resistant epilepsy. Furthermore, in one rodent model, its efficacy extended beyond the combination of drugs interacting separately with SV2 or the benzodiazepine site. Padsevonil displayed a high therapeutic index, potentially translating into a favorable safety profile in humans; tolerance to antiseizure effects was not observed.

\section{Introduction}

Epilepsy is one of the most common neurologic diseases worldwide, and is associated with a significant healthcare burden (Devinsky et al., 2018; Thijs et al., 2019). For most patients with epilepsy, antiepileptic drugs (AEDs) are the mainstay of therapy, which must be taken on a long-term,

All studies described in this report were funded by UCB Pharma.

All authors are current or former employees of UCB Pharma.

${ }^{1}$ Current affiliation: Roche Innovation Center Basel, Hoffmann-La Roche Ltd., Basel, Switzerland.

https://doi.org/10.1124/jpet.119.261222. often lifelong basis (Trinka, 2012; Thijs et al., 2019). Antiepileptic drugs approved in the last decade display good safety and pharmacokinetic profiles; however, thus far improved efficacy over first-generation AEDs has not been demonstrated in clinical studies (Chen et al., 2018), and approximately one-third of patients with epilepsy continue to experience poorly controlled seizures despite treatment, i.e., drug-resistant epilepsy (Kwan et al., 2010; Kalilani et al., 2018; Chen et al., 2018). Most AEDs were discovered by initial demonstration of their antiseizure activity in simple, classic seizure models, such as the maximal electroshock (MES) and pentylenetetrazol (PTZ) tests, which

ABBREVIATIONS: ADD, afterdischarge duration; AED, antiepileptic drug; BRV, brivaracetam [2S-2-[(4R)-2-oxo-4-propylpyrrolidin-1-yl] butanamide]; BZD, benzodiazepine; CBZ, carbamazepine [5-carbamoyl-5H-dibenzo(b,f)azépine]; DZP, diazepam [7-chloro-1-méthyl-5-phényl$3 \mathrm{H}$-1,4-benzodiazepine-2-one]; EEG, electroencephalogram; GABA $R$, GABA $A_{A}$ receptor; GAERS, Genetic Absence Epilepsy Rats from Strasbourg; HPD, hippocampal paroxysmal discharge; LEV, levetiracetam [2S-(2-oxo-1-pyrrolidinyl)butanamide]; MES, maximal electroshock; PHT, phenytoin [5,5-diphénylimidazolidine-2,4-dione]; PSL, padsevonil [(4R)-4-(2-chloro-2,2-difluoroethyl)-1-\{[2-(methoxymethyl)-6-(trifluoromethyl)imidazo[2,1-b] $[1,3,4]$ thiadiazol-5-yl]methyl\}pyrrolidin-2-one]; PTZ, pentylenetetrazol; SV2, synaptic vesicle protein 2; SWD, spike and wave discharge; TI, therapeutic index; VPA, valproate. 
are highly predictive of clinical efficacy in epilepsy, but not drug-resistant epilepsy (Löscher et al., 2013).

Polytherapy is a frequent treatment strategy for patients with drug-resistant epilepsy, since a substantial proportion will require more than one AED to reduce their seizure burden (French and Faught, 2009; Brodie and Sills, 2011). The combination of selected AEDs should allow for synergistic or additive efficacy without any detrimental impact on safety and tolerability (French and Faught, 2009; Brodie and Sills, 2011); however, a nonclinical mechanistic rationale for clinically used AED combinations is often lacking or has not yet translated into superior efficacy.

$2 S$-(2-oxo-1-pyrrolidinyl)butanamide [levetiracetam (LEV)] is an AED that exerts its therapeutic activity primarily by binding to the synaptic vesicle protein 2 (SV2) A protein (Lynch et al., 2004) and shows a distinctive profile in nonclinical seizure models. While ineffective in standard models used traditionally in AED discovery, such as the MES and PTZ tests, LEV provided protection against seizures in models of acquired and genetic epilepsies (Klitgaard et al., 1998), subsequently translating to broad-spectrum clinical efficacy in humans (Klitgaard and Verdru, 2007). In the audiogenic seizure and amygdala kindling models, LEV increased the potency of several AEDs and experimental agents that interfere with ligand-gated ion channels, particularly those that enhance GABA-mediated inhibition (Kaminski et al., 2009). Importantly, the increase in potency was devoid of additional adverse effects (i.e., motor impairment) as assessed by the rotarod test; on the contrary, it was associated with an increase in the therapeutic index (Kaminski et al., 2009). Assuming a potential synergistic interaction between ligands that act via SV2 and $\mathrm{GABA}_{\mathrm{A}}$ receptors $\left(\mathrm{GABA}_{\mathrm{A}} \mathrm{Rs}\right)$, a rational medicinal chemistry design program was initiated to develop a single molecular entity that could target both.

The outcome of this discovery program was the identification of (4R)-4-(2-chloro-2,2-difluoroethyl)-1-\{[2-(methoxymethyl)6-(trifluoromethyl)imidazo[2,1-b] [1,3,4]thiadiazol-5-yl] methyl\}pyrrolidin-2-one [padsevonil (PSL)], the first rationally designed AED candidate that acts selectively on both pre- and postsynaptic targets. Presynaptically, as a SV2 ligand, PSL displays high affinity (nanomolars), not only for SV2A but also for the other two protein isoforms, SV2B and SV2C. The latter markedly distinguishes the profile of PSL from that of LEV and 2S-2-[(4R)-2-oxo-4-propylpyrrolidin-1yl] butanamide [brivaracetam (BRV)], which are selective SV2A ligands that, therefore, have no established postsynaptic activity. Postsynaptically, as a positive allosteric modulator of $\mathrm{GABA}_{\mathrm{A}} \mathrm{Rs}$, PSL displays low-to-moderate (in micromolars) binding affinity for the benzodiazepine (BZD) site in recombinant human $\mathrm{GABA}_{\mathrm{A}} \mathrm{Rs}$ and human and rat brain membrane preparations, where it shows a partial agonist profile(Wolff et al., 2017). This profile was selected specifically to minimize central nervous system and respiratory adverse effects, tolerance development, and abuse potential typically associated with the use of BZDs that are full agonists (Rundfeldt and Löscher, 2014). The detailed pharmacological and mechanistic profile of PSL is described in the companion paper (Wood et al., 2019). In this report, we describe the activity of PSL in a variety of rodent seizure and epilepsy models and compare its activity with that of mechanistically diverse and clinically used AEDs. We also compare the potential of PSL for development of tolerance with that of the BZD, diazepam (DZP), after chronic dosing in mice.

\section{Materials and Methods}

\section{Animals}

All experiments were conducted in compliance with guidelines issued by the ethics committee for animal experimentation according to Belgian law. Those conducted as part of the murine intrahippocampal kainate model of mesial temporal lobe epilepsy were performed at Synapcell (Grenoble, France). The experiments were approved by the European Technology Platform for Global Animal Health and performed in accordance with the European Committee Council directive (2010/63/EU). All efforts were made to minimize animal suffering.

Female, genetically sound-sensitive mice (20-24 g) were derived from a DBA strain from the Laboratory of Acoustic Physiology (Paris, France) and bred at Charles River Laboratories (Italy). Male NMRI mice weighing 20-35 g were used in all other acute electrically and chemically induced seizure tests, as well as in the rotarod and tolerance tests. Male C57BL/6J mice, weighing 25-34 $\mathrm{g}$, were used for the murine model of amygdala kindling. For the rat model of amygdala kindling, male Sprague-Dawley rats weighing $300-350 \mathrm{~g}$ at the initiation of kindling were used. Male Wistar rats of the Genetic Absence Epilepsy Rats from Strasbourg (GAERS) strain were used at a body weight of 280-400 g. Male SpragueDawley rats (200-240 g) were used for the rotarod tests. Animals were obtained from Charles River Laboratories (France) and housed in a holding room under a 12-hour light-dark cycle with lights on at 6:00 AM. Temperature was maintained at $20-24^{\circ} \mathrm{C}$, relative humidity was maintained at $40 \%-70 \%$, and the rate of air replacement was at least 15 times an hour. Animals had ad libitum access to standard dry pellet food and tap water.

For the intrahippocampal kainate model, male C57BL/6 mice (11 weeks of age) were obtained from Janvier (France) and housed in cages on wood litter for 8 days with free access to food and water until surgery. Animal housing was maintained under artificial lighting from 8:00 AM to 8:00 PM.

\section{Drugs and Chemicals}

PSL, LEV, and BRV were synthesized at UCB Pharma (Brainel'Alleud, Belgium). All other reagents were of analytical grade and were obtained from conventional commercial sources. PSL was dissolved in $10 \mathrm{mM}$ citrate buffer, $1.5 \%$ methylcellulose, $0.1 \%$ Tween 80 , and $0.1 \%$ silicone antifoam, and LEV and BRV were dissolved in saline.

\section{Experimental Procedures}

Murine Models of Acutely Induced Seizures. Methods for the audiogenic, electrically, and chemically induced seizure models have been previously described in detail (Jackson et al., 1996; Klitgaard et al., 1998; Kaminski et al., 2008, 2011; Leclercq and Kaminski, 2015).

For the audiogenic seizures model, mice were placed (one at a time) in a sound-attenuated chamber, where audiogenic seizures were induced through application of an acoustic stimulus (85 dB at 10-20 $\mathrm{kHz}$ for 30 seconds). The proportion of mice protected against clonic seizures was used to determine antiseizure activity. This endpoint was chosen because a correlation between SV2A affinity and efficacy against clonic seizures has been previously demonstrated (Kaminski et al., 2008).

For electrically induced seizures, the MES and $6 \mathrm{~Hz}$ models were used. In MES, $50 \mathrm{~mA}$ currents were delivered at a constant pulse frequency of $50 \mathrm{~Hz}$ and duration of 0.2 seconds. The proportion of mice protected against tonic hindlimb extension after stimulation was used to determine antiseizure activity, as well as dose-response curve. 
In the $6 \mathrm{~Hz}$ model, $44 \mathrm{~mA}$ currents were delivered with 0.2-millisecond monopolar pulses at $6 \mathrm{~Hz}$ for a duration of 3 seconds. After stimulation, mice were observed for 30 seconds and the duration of immobility (stunned posture) was noted. The proportion showing immobility for $<7$ seconds was used as the endpoint for seizure protection, as previously described (Leclercq and Kaminski, 2015).

For the chemically induced seizure models, PTZ $(89 \mathrm{mg} / \mathrm{kg})$ and bicuculline ( $3 \mathrm{mg} / \mathrm{kg}$ ) were administered subcutaneously, and pilocarpine $(373 \mathrm{mg} / \mathrm{kg})$ was administered intraperitoneally. In the latter model, the peripheral cholinergic effect was blocked via administration of methylscopolamine ( $1 \mathrm{mg} / \mathrm{kg}$, i.p.) 30 minutes before administration of pilocarpine. The proportion of mice protected against clonic seizures in all four extremities during a 60-minute observation period after drug administration was used to determine antiseizure activity. 11-Deoxycortisol (1.0-1.2 $\mathrm{mmol} / \mathrm{kg})$ was infused through the lateral tail vein, and protection against generalized seizures during the 60minute observation period after infusion was used to assess antiseizure activity.

In all experiments, PSL was tested at doses ranging from 0.014 to $181.4 \mathrm{mg} / \mathrm{kg}$, which was administered $(10 \mathrm{ml} / \mathrm{kg}) 30$ minutes before testing, except for audiogenic seizure testing, where the preadministration time was 15 minutes. Testing was initiated in the audiogenic model before having conducted thorough pharmacokinetics assessment; preadministration time was subsequently adapted for screening in other models. Each experiment consisted of independent groups of 10-14 mice, with one group receiving vehicle (control) and the others receiving different PSL doses. The experimenter was unaware of the nature of the compound administered.

Comparative $6 \mathrm{~Hz}$ Study. The $6 \mathrm{~Hz}$ model was used to compare the protective effect of PSL with that of LEV, BRV, and DZP, as well as the combination of LEV or BRV with DZP. To allow for a direct, objective comparison, drugs were administered at doses to provide similar in vivo target occupancy. PSL was administered at a dose of $0.17 \mathrm{mg} / \mathrm{kg}$, which is expected to provide $2 \%$ and $35 \%$ occupancy at the BZD site and SV2A, respectively, based on results of in vivo occupancy studies (Wood et al., 2019). Correspondingly, LEV and BRV were tested at 1.83 and $0.42 \mathrm{mg} / \mathrm{kg}$, respectively, to provide $35 \% \mathrm{SV} 2 \mathrm{~A}$ occupancy, and DZP was tested at $0.017 \mathrm{mg} / \mathrm{kg}$ to provide $2 \%$ occupancy at the BZD site. All drugs were administered intraperitoneally 30 minutes before testing except for LEV, which was administered 60 minutes before testing. Each experimental arm consisted of 15 or 16 mice.

Amygdala Kindling. Protocols used for both mouse and rat amygdala kindling experiments have been described previously (Löscher et al., 1986). For the rat model, experiments consisted of five groups of eight fully kindled rats, each group receiving different doses of PSL (0.14-13.9 mg/kg) administered intraperitoneally $(5 \mathrm{ml} / \mathrm{kg})$ 30 minutes before stimulation with the same supra-maximal current (500 $\mu \mathrm{A}$ at 1 second) used for the induction of kindling. Similarly, six groups of eight to nine mice received different doses of PSL (0.014-13.85 $\mathrm{mg} / \mathrm{kg}$ ) administered intraperitoneally 30 minutes before testing with the same supra-maximal stimulation current $(250 \mu \mathrm{A}$ at 1 second) used for the induction of kindling. Additionally, similar experiments were conducted in groups of mice receiving BRV, carbamazepine (CBZ), DZP, LEV, lamotrigine, phenytoin (PHT), topiramate, retigabine, or valproate (VPA).

The effects of drugs on three parameters were tested in fully kindled animals. First, as a measure of the drug's effect on seizure severity, the behavioral effects of the stimulation were scored according to the scale described by Racine (1972), where $0=$ no reaction, $1=$ blinking and/or mild facial twitches and chewing, $2=$ head nodding and/or severe facial clonus, $3=$ myoclonic jerks of the forelimbs, $4=$ clonic seizures of the forelimbs with rearing, and $5=$ generalized clonic seizures associated with loss of balance. Second, the proportion of animals protected against generalized seizures (scores $3-5)$ was used to determine the drugs' $\mathrm{ED}_{50}$ values and antiseizure activity. Third, the electroencephalographic effect of the stimulation was determined by measuring the stimulationinduced afterdischarge duration (ADD), defined as electroencephalogram (EEG) activity with an amplitude at least twice that of the prestimulus recording and a frequency $>1 \mathrm{~Hz}$.

Murine Intrahippocampal Kainate Mouse Model of Mesial Temporal Lobe Epilepsy. Experiments were performed as previously described (Riban et al., 2002; Duveau et al., 2016). Briefly, male C57BL/6 mice $(n=20)$ were surgically injected with kainate $(1 \mathrm{nmol})$ in the right dorsal hippocampus. Bipolar electroencephalography electrodes were implanted into the injected hippocampus, with additional monopolar surface electrodes placed over the frontoparietal cortex and cerebellum. After a 5-week period of epileptogenesis, mice $(n=9)$ displaying hippocampal paroxysmal discharges [(HPDs); $\geq 20 / \mathrm{h}$ ] without any generalized seizures were selected. Baseline EEG (20 minutes) was recorded before injection of vehicle $(10 \mathrm{mM}$ citrate buffer, $1.5 \%$ methylcellulose, $0.1 \%$ Tween 80 , and $0.1 \%$ silicone antifoam) or PSL (1,3,10, or $30 \mathrm{mg} / \mathrm{kg}$, i.p.) and recording continued for an additional 90 minutes. Stress induced by handling and drug administration caused a transient decrease in the number of HPDs, as observed reproducibly in vehicle-treated animals. Therefore, the number and duration of HPDs were measured and analyzed for 80 minutes, after discarding the first 10-minute postdrug administration. PSL doses were administered in a randomized crossover manner.

Spike-Wave Discharges in Genetic Absence Epilepsy Rat from Strasbourg. Four platinum electrodes were implanted bilaterally in the frontal and occipital cortices as described previously (Matagne et al., 2009). After a 2 -week recovery period, rats were injected with either vehicle or PSL and the EEG was recorded continuously over consecutive 20-minute intervals starting 20 minutes before and up to 120 minutes after drug administration. The cumulative duration of spontaneous spike and wave discharges (SWDs) in each 20-minute interval was measured by a semiautomatic program. PSL was administered at doses equal to $0.14,0.43,1.38$, and $4.33 \mathrm{mg} / \mathrm{kg}$ in a dose volume of $5 \mathrm{ml} / \mathrm{kg} \mathrm{b} . \mathrm{wt}$. The control group received vehicle injection intraperitoneally ( $5 \mathrm{ml} / \mathrm{kg}$ b.wt.). Eight rats were used in these experiments with a crossover design in which each animal served as its own control after injection of vehicle.

Tolerance. To determine whether mice developed tolerance to PSL's antiseizure effects, its impact on the PTZ-induced clonic seizure threshold was tested. For comparison, the tolerance potential of diazepam, a full agonist at the BDZ site, was also evaluated. This test is widely described as a nonclinical tool for assessment of tolerance-like effects of AEDs (Rundfeldt et al., 1995). Briefly, the test consists of two steps. In the first step, the PTZ threshold dose for inducing seizures and the $\mathrm{ED}_{97}$ value of a given AED in providing protection against these PTZ-induced clonic seizures are determined. In the subsequent step, tolerance to the protective effect of the AED after repeated administration is determined.

For the first step, an intravenous infusion of PTZ $(5 \mathrm{mg} / \mathrm{ml})$ was administered into the tail vein of freely moving mice and the time to the three stages of seizures (twitch, clonic, and tonic) was noted. Padsevonil, DZP, or vehicle was administered intraperitoneally $(10 \mathrm{ml} / \mathrm{kg}) 30$ minutes before PTZ infusion to determine the dose that increased the PTZ threshold dose by $97 \%\left(\mathrm{ED}_{97}\right)$. Different treatments were randomly distributed within each group of mice $(6,8$, or 10 mice per group for PSL, and 6, 10, or 11 mice per group for DZP experiments) with injections at 5-minute intervals. In the second step, mice were administered with the previously selected PSL/DZP dose $\left(\mathrm{ED}_{97}\right)$ or vehicle, twice daily, for four consecutive days $(n=12$ each group). On day 5, they were treated with PSL/DZP or vehicle 30 minutes before assessment of their respective seizure threshold, following intravenous infusion of PTZ. There were four experimental groups, as described in Table 1.

Rotarod. The impact of PSL on motor activity was evaluated using the rotarod test in both mice and rats using previously described 
TABLE 1

Experimental groups in the pentylenetetrazol-induced clonic seizure threshold test

\begin{tabular}{|c|c|c|}
\hline Experimental Group & Days $1-4$ & Day 5 \\
\hline 1 & Vehicle (twice daily) & Vehicle (administered 30 min before intravenous PTZ) \\
\hline 2 & Vehicle (twice daily) & PSL/DZP at $\mathrm{ED}_{97}$ (administered 30 min before intravenous PTZ) \\
\hline 3 & PSL/DZP at $\mathrm{ED}_{97}$ (twice daily) & Vehicle (administered 30 min before intravenous PTZ) \\
\hline
\end{tabular}

protocols (Klitgaard et al., 1998). Animals were trained and only those able to remain on the rod for at least 60 seconds in three consecutive trials were used in the tests. In mice, PSL was administered intraperitoneally $(10 \mathrm{ml} / \mathrm{kg}) 30$ minutes before testing; one group (control) received vehicle and the others received PSL doses of $4.3-77.9 \mathrm{mg} / \mathrm{kg}$ ( $n=10$ each group). In rats, PSL was administered intraperitoneally $(5 \mathrm{ml} / \mathrm{kg}) 30$ minutes before testing; one group (control) received the vehicle and the others received PSL doses of $4.3-43.3 \mathrm{mg} / \mathrm{kg}$ ( $n=8$ each group). The median tolerated dose, at which toxicity or impairment of motor coordination occurs in $50 \%$ of animals $\left(\mathrm{TD}_{50}\right)$ was calculated and used to determine the therapeutic index (TI) of PSL. The TI is defined as the ratio between doses producing motor impairment $\left(\mathrm{TD}_{50}\right)$ and doses providing protection against seizures $\left(\mathrm{ED}_{50}\right)$. To compare the TI of PSL with that of other AEDs in the amygdala kindling model, the $\mathrm{TD}_{50}$ values of the following drugs were also determined in naive mice: BRV, CBZ, DZP, LEV, lamotrigine, PHT, topiramate, retigabine, and VPA.

\section{Data Analysis}

Unless otherwise noted, the $\mathrm{ED}_{50}$ values and associated $95 \%$ confidence intervals were calculated using nonlinear fitting of the doseresponse curve with GraphPad Prism version 4 (GraphPad Software, San Diego, CA). In the $6 \mathrm{~Hz}$ comparative study, Fisher's exact test was used for statistical comparisons of the number of animals protected with PSL and with the combinations of LEV or BRV with DZP using GraphPad Prism (as previously described).

Amygdala Kindling. Significant differences between compound and vehicle in the median behavioral seizure score, protection against generalized seizures, and the ADD were evaluated with the Wilcoxon signed rank test, Fisher's exact test, and Mann-Whitney $U$ test, respectively. All statistical analyses were performed with GraphPad Prism (as previously described).

Intrahippocampal Kainate Model. Statistical analyses were performed with GraphPad Prism version 7 using two-way ANOVA for repeated measures, with the factors of time and compound dose (with repeated measures applying only to the time factor), followed by Bonferroni's multiple comparisons test.

Spike-Wave Discharges in GAERS. For each treatment, the mean cumulative duration of SWDs ( \pm S.E.M. $)$ was calculated for each 20 -minute interval. The results for each 20 -minute interval were compared with those of vehicle treatment using two-way ANOVA with repeated measures, followed by a post hoc Bonferroni multiple comparisons test $(P<0.05)$, using GraphPad Prism. Due to the high variability of the responses observed in each 20-minute interval for different rats, data were further analyzed using the cumulative duration of SWDs covering the total postdrug observation period (120 minutes). This allowed application of nonlinear regression curve fitting of the results and estimation of the protective $\mathrm{ED}_{50}$.

Tolerance. The effective dose increasing the PTZ threshold by $97 \%\left(\mathrm{ED}_{97}\right)$ was calculated using nonlinear fitting of individual values of the dose-response curve (SAS/STAT ${ }^{\mathrm{R}}$ Software version 9.1). Oneway ANOVA and Tukey's multiple comparisons test were performed with individual calculated doses of PTZ inducing clonic seizures in the four groups of mice. Statistically significant differences between chronic vehicle + test compound $\mathrm{ED}_{97}$ dose and chronic test compound $\mathrm{ED}_{97}$ dose + test compound $\mathrm{ED}_{97}$ dose were used to assess development of tolerance.

\section{Results}

Murine Models of Acutely Induced Seizures. Administration of PSL provided potent, dose-dependent protection against seizures induced by $6 \mathrm{~Hz}$ stimulation, acoustic stimulus, and a bolus dose of pilocarpine $\left(\mathrm{ED}_{50}\right.$ values of $0.16,0.17$, and $0.19 \mathrm{mg} / \mathrm{kg}$, respectively). The potency of PSL in these three models was greater than that of LEV and BRV (ineffective in the pilocarpine model) (Table 2). PSL also provided dose-dependent protection against clonic seizures induced by a bolus dose of PTZ. Its potency in this model was higher than that of BRV, while LEV was ineffective. In the 11deoxycortisol model, PSL provided dose-dependent and almost complete protection against seizures; at the highest dose tested $(43.3 \mathrm{mg} / \mathrm{kg}), 90 \%$ of animals were protected. Brivaracetam was ineffective in this model, while LEV provided only limited protection at the highest doses tested. PSL showed low potency against seizures induced by a bolus of bicuculline, while LEV and BRV were ineffective in this model. The lowest potency was seen in the MES model $\left(\mathrm{ED}_{50}\right.$ value of $\left.92.8 \mathrm{mg} / \mathrm{kg}\right)$. The lack of activity or low potency in this model was also observed with LEV and BRV.

Comparative $6 \mathrm{~Hz}$ Study. The protective effect of PSL in the $6 \mathrm{~Hz}$ model was compared with that of LEV, BRV, and DZP alone, and with the combinations of LEV or BRV with DZP at doses expected to provide similar occupancy at SV2A (35\%) or the BZD site (2\%). PSL protected a greater proportion of mice than LEV, BRV, and DZP alone or in combination (Fig. 1). The difference in the protection offered by PSL and that of the LEV/DZP and BRV/DZP combinations was statistically significant $(P=0.021$ and $P=0.0008$, respectively; Fisher's exact test). The difference in the protection provided by BRV and the

\section{TABLE 2}

Potency of padsevonil and selective SV2A ligands in murine models of acutely induced seizures

All drugs were administered intraperitoneally $15 \mathrm{~min}$ before testing in the audiogenic seizure model (administered intraperitoneally $30 \mathrm{~min}$ in the other models).

\begin{tabular}{lccc}
\hline \multirow{2}{*}{ Model } & \multicolumn{3}{c}{$\mathrm{ED}_{50}$} \\
\cline { 2 - 4 } & \multicolumn{1}{c}{ Padsevonil } & Brivaracetam & Levetiracetam \\
\hline & $m g / k g$ & $m g / k g$ & $m g / k g$ \\
$6 \mathrm{~Hz}$ & $0.16(0.1-0.2)$ & $4.4^{a}$ & $19.2^{a}$ \\
Audiogenic & $0.17(0.1-0.2)$ & $2.4^{a}$ & $30^{a}$ \\
Pilocarpine & $0.19(0.1-0)$ & $\mathrm{NE}^{a}$ & $7.1^{b}$ \\
Pentylenetetrazol & $4.8(1.7-10.8)$ & $30^{a}$ & $\mathrm{NE}^{a}$ \\
11-deoxycortisol & $9.9(4.6-21.0)$ & $\mathrm{NE}^{c}$ & $540^{c} d$ \\
Bicuculline & $27.3(17.2-43.1)$ & $\mathrm{NE}^{b}$ & $\mathrm{NE}^{b}$ \\
Maximal electroshock & $92.8(74.3-115.9)$ & $113^{a}$ & $\mathrm{NE}^{a}$ \\
& & &
\end{tabular}

NE, not effective

${ }^{a}$ Klitgaard et al. (2016)

${ }^{b}$ Klitgaard et al. (1998).

${ }^{c}$ Kaminski et al. (2011).

${ }^{d}$ Minimally active dose, defined as the lowest dose providing statistically significant protection against seizures. 


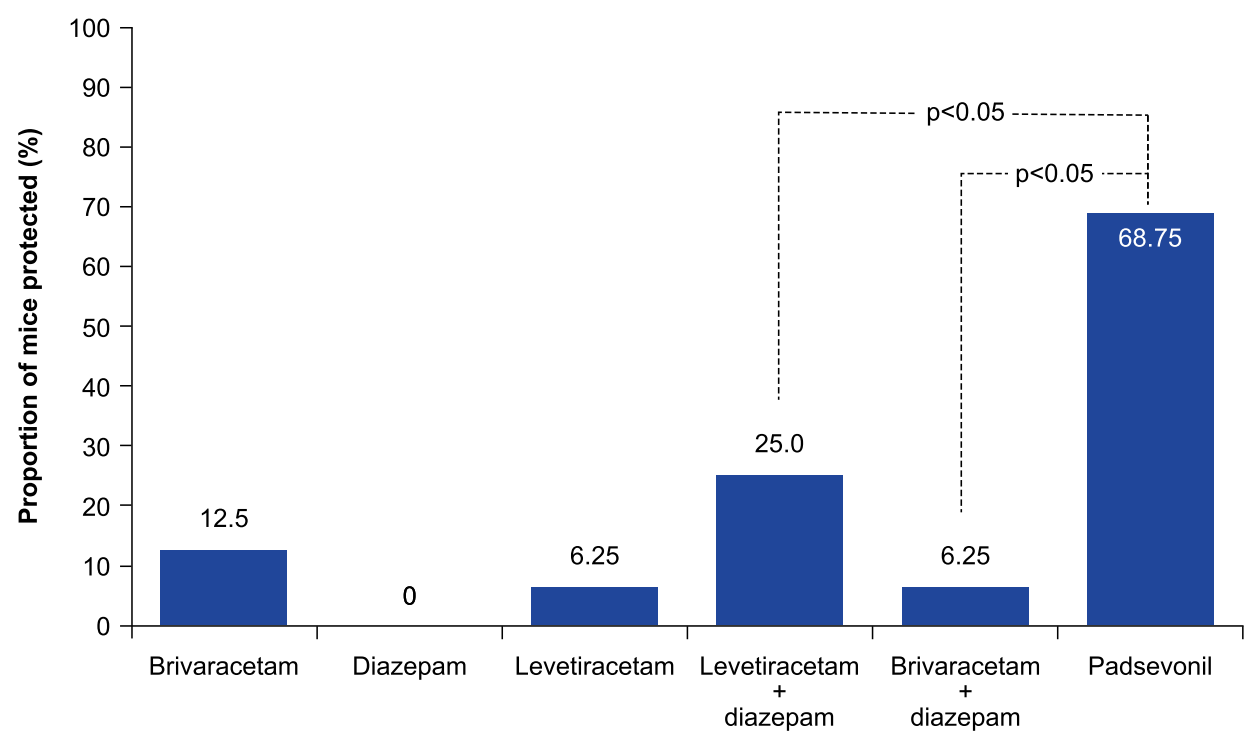

Fig. 1. Protective effect of padsevonil $(0.17 \mathrm{mg} / \mathrm{kg})$ in the $6 \mathrm{~Hz}$ model compared with that of levetiracetam $(1.83 \mathrm{mg} / \mathrm{kg})$, brivaracetam $(0.42 \mathrm{mg} / \mathrm{kg})$, and diazepam $(0.017 \mathrm{mg} / \mathrm{kg})$, as well as the combination of diazepam with levetiracetam or brivaracetam. The drugs were administered at doses associated with similar in vivo SV2A $(35 \%)$ and benzodiazepine site $(2 \%)$ occupancies (comparisons were made using Fisher's exact test).
BRV/DZP combination or the LEV and LEV/DZP combination was not significant ( $P=0.4$ and $P=0.145$, respectively).

Amygdala Kindling. The protective effect of PSL against seizures was evaluated in fully kindled animals using three parameters. In rats, PSL provided dose-dependent and complete protection against focal to bilateral seizures (secondary generalized seizures). The reduction in the proportion of rats displaying generalized seizures at doses of $2.4,4.3$, and $13.9 \mathrm{mg} / \mathrm{kg}$ was statistically significant, with $100 \%$ of animals protected at the highest dose (Fig. 2, right panel). The $\mathrm{ED}_{50}$ value was estimated to be $2.43(2.41-2.46) \mathrm{mg} / \mathrm{kg}$. Significant, dose-dependent reductions in the median seizure severity score and ADD were also observed with PSL, starting from a dose of $2.4 \mathrm{mg} / \mathrm{kg}$.

In mice, just as in rats, PSL significantly reduced the proportion of animals with focal to bilateral seizures and the median seizure severity score starting from a dose of $1.4 \mathrm{mg} / \mathrm{kg}$ (Fig. 2, left panel). Based on the proportion of mice protected from focal to bilateral seizures (secondary generalized seizures), the $\mathrm{ED}_{50}$ value was estimated to be $1.2(0.43-3.40)$ $\mathrm{mg} / \mathrm{kg}$. PSL also reduced the ADD, but only at the highest dose tested $(13.9 \mathrm{mg} / \mathrm{kg})$; at lower doses an increase was observed, with the increase $(40 \%)$ at the $1.38 \mathrm{mg} / \mathrm{kg}$ dose being statistically significant.

The TI of PSL in kindled mice was 9.8, which was relatively high compared with that of BRV and VPA, 2.8 and 1.2, respectively (Table 3). Other AEDs tested in this model displayed only partial protection against generalized seizures; therefore, it was not possible to calculate their TI.

Intrahippocampal Kainate Model. PSL administration $(1,3,10$, or $30 \mathrm{mg} / \mathrm{kg})$ resulted in dose-dependent and statistically significant reductions in the number of HPDs compared with vehicle or baseline, between 30 and 70 minutes after administration. PSL doses of 10 and $30 \mathrm{mg} / \mathrm{kg}$ were associated with significant reductions in the number of HPDs from 10 to 30 minutes after administration (Fig. 3, top panel). Dosedependent effects of PSL were also observed when the cumulated duration of HPDs was calculated, with all PSL doses associated with significant reductions compared with vehicle 50-70 minutes after administration. Maximal effects were observed with 10 and $30 \mathrm{mg} / \mathrm{kg}$ doses after 10-30 minutes (Fig. 3, bottom panel).
Spike and Wave Discharges in GAERS. PSL $(0.14-4.33 \mathrm{mg} / \mathrm{kg})$ produced dose-related suppression in spontaneous SWDs, which was statistically significant from the $0.43 \mathrm{mg} / \mathrm{kg}$ dose-the suppression was almost complete at a dose of $4.33 \mathrm{mg} / \mathrm{kg}$ (Fig. 4). The effect was apparent in the first 20-minute test interval and persisted throughout the recording period (up to 120 minutes). Treatment with PSL also resulted in dose-dependent reduction in the cumulative duration of spontaneous SWDs recorded over the 120-minute postdrug period $\left(\mathrm{ED}_{50}\right.$ value of $\left.0.87 \mathrm{mg} / \mathrm{kg}\right)$.

Tolerance. Having established the PTZ threshold dose for inducing clonic seizures, PSL and DZP were tested. Both drugs increased the seizure threshold in a dose-dependent manner; the $\mathrm{ED}_{97}$ of PSL was $15.9 \mathrm{mg} / \mathrm{kg}$ and that of DZP was $2.1 \mathrm{mg} / \mathrm{kg}$.

Animals that were treated twice daily for 4 days with vehicle, PSL, or DZP at the calculated $\mathrm{ED}_{97}$ dose were injected again on day 5 with the same dose before assessment of the seizure threshold following intravenous PTZ infusion. Treatment with PSL ( $15.9 \mathrm{mg} / \mathrm{kg}$ ) caused a significant increase in the PTZ threshold dose with a similar magnitude in both groups (mice chronically treated with vehicle or drug). The difference in the mean doses of PTZ that induced seizures in mice treated chronically with vehicle and those treated chronically with PSL was not statistically significant (Fig. 5).

Diazepam $(2.1 \mathrm{mg} / \mathrm{kg})$ also caused a significant increase in the PTZ threshold dose for clonic seizures in both groups, but with a much lower magnitude in mice chronically treated with DZP, reflecting development of tolerance to its antiseizure effects. The mean dose of PTZ inducing clonic seizures in mice treated chronically with the vehicle was comparable to the mean dose calculated in mice treated chronically with DZP (Fig. 5).

Rotarod. Administration of PSL resulted in dosedependent impairment in the performance of both mice and rats in the rotarod test; the $\mathrm{TD}_{50}$ values were $11.8(9.2-15.2)$ and 24.4 (15.0-39.7) $\mathrm{mg} / \mathrm{kg}$, respectively. The TI of PSL was calculated using these values and the $\mathrm{ED}_{50}$ values determined in various models. PSL had a TI of 28 in the GAERS and 10 in the rat amygdala kindling models. In mice, the TI 

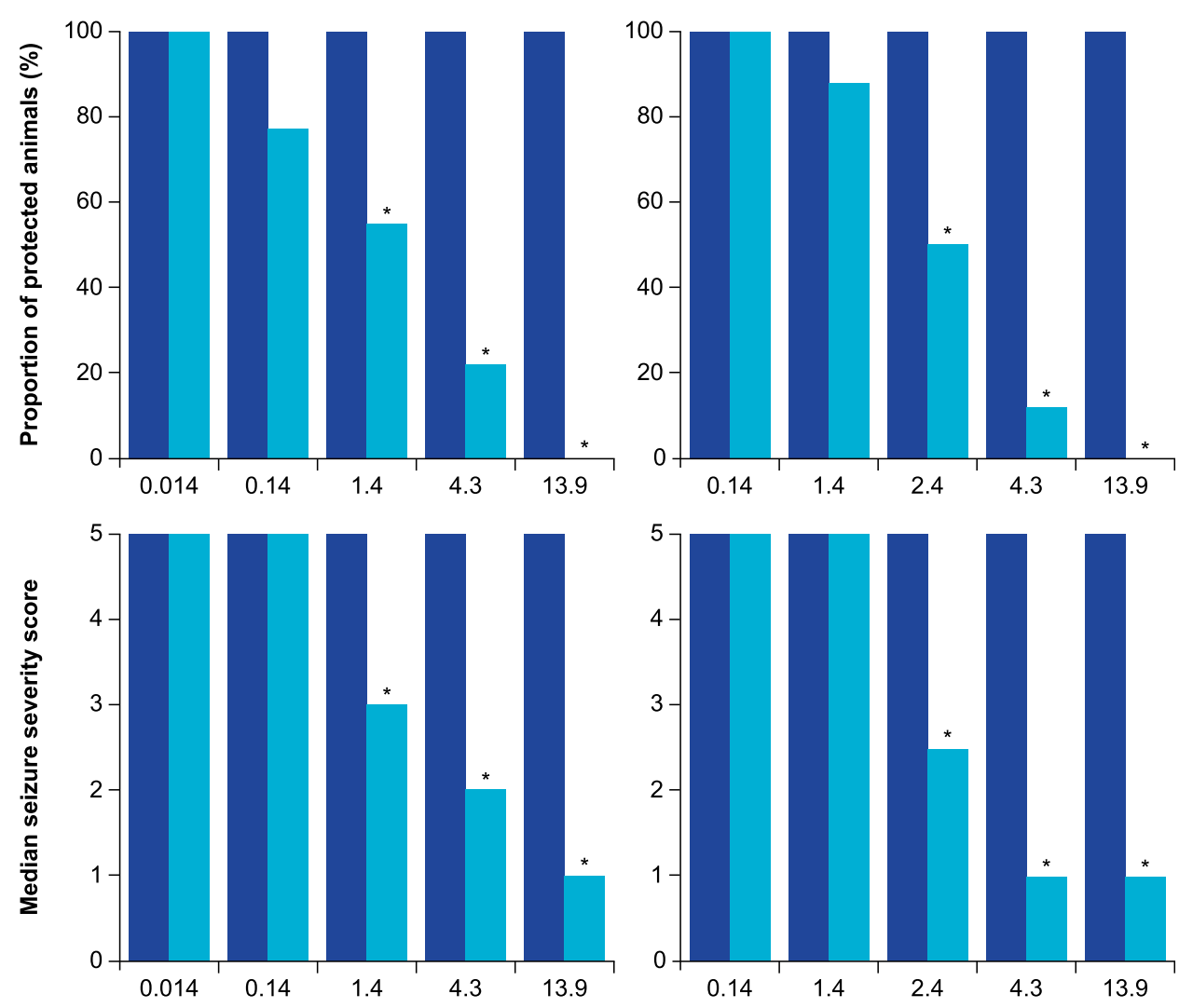

Fig. 2. Effect of padsevonil on seizure parameters recorded after supra-threshold stimulation in fully kindled rats (right panel) and mice (left panel). Control recordings were performed 48 hours before testing with padsevonil. Values are mean \pm S.E.M. for afterdischarge duration. Comparisons between drug and control in protection against generalized seizures, seizure severity score, and afterdischarge duration were evaluated with Wilcoxon signed rank test Fisher's exact test, and Mann-Whitney $U$ test, respectively, with * indicating statistically significant differences $(P<0.05)$.
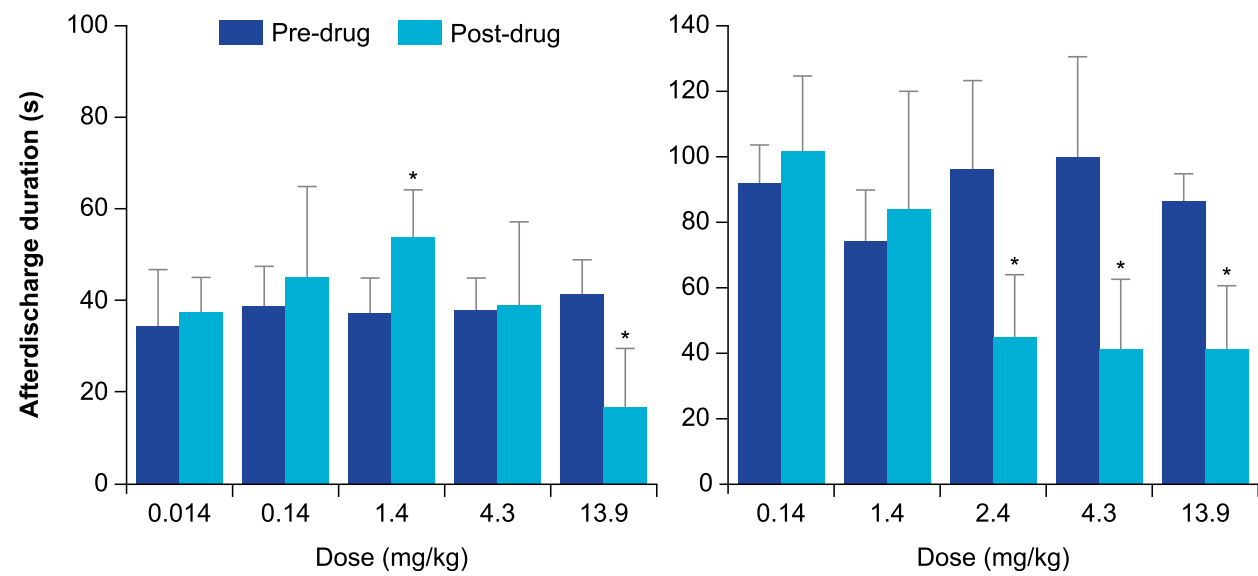

was calculated to be 69 in the audiogenic, 62 in the pilocarpine-induced, 74 in the $6 \mathrm{~Hz}$-induced, and 2.5 in the PTZ-induced seizure tests. As noted previously, the TI in the murine amygdala kindling model was 9.8.

\section{Discussion}

PSL is the first in a novel class of drugs that bind to SV2 proteins and the BZD site on $\mathrm{GABA}_{\mathrm{A}}$ Rs. As shown in the studies reported here, this pre- and postsynaptic activity results in a distinct pharmacological profile across a wide range of seizure and epilepsy models representing focal and generalized epilepsy in humans.

The MES and PTZ tests, considered gold standards for early detection of antiseizure activity, are used for screening candidate compounds (Klitgaard, 2005; Bialer and White, 2010). LEV is inactive in both models, while BRV, a more potent and selective SV2A ligand than LEV shows weak activity in both models (Matagne et al., 2008). Similarly, PSL showed activity in both models, but its potency, while greater than that of BRV, was also relatively weak. PSL's effect was greater in the PTZ than in the MES test, which is likely to be mediated partially via the BZD site, since BZDs show high potency in this model (Löscher, 2011). PSL also showed relatively low potency in the bicuculline test, where typical BZDs are active, but not abecarnil, a partial agonist at the BZD site (Turski et al., 1990); consequently, low activity was expected, since both LEV and BRV are inactive in this test and PSL shows a partial agonist profile.

PSL provided potent, dose-dependent protection against seizures induced in sound-sensitive mice, a genetic model of generalized epilepsy. BRV is active in this model, while LEV shows lower potency, correlating with their SV2A binding affinity (Kaminski et al., 2008; Matagne et al., 2008). PSL also 
TABLE 3

Comparison of the therapeutic index of padsevonil and nine other antiepileptic drugs with different mechanisms of action determined in the mouse amygdala kindling model and rotarod test.

Other than padsevonil, brivaracetam, and valproate, the $\mathrm{ED}_{50}$ values—and, therefore, the therapeutic index of the other antiepileptic drugs — could not be calculated.

\begin{tabular}{|c|c|c|c|c|c|}
\hline Drug & Amygdala Kindling $\mathrm{ED}_{50}$ & MAD/Protection Against Seizures ${ }^{a}$ & MTD/Protection Against Seizures ${ }^{a}$ & Rotarod Test $\mathrm{TD}_{50}$ & Therapeutic Index \\
\hline & $m g / k g$ & $(m g / k g) / \%$ & $(m g / k g) / \%$ & $m g / k g$ & \\
\hline Padsevonil & $1.2(0.4-3.4)$ & $1.4 / 60$ & $13.9 / 100$ & $12(9-15)$ & 9.8 \\
\hline Brivaracetam & $68(39-118)$ & $134 / 90$ & $212 / 91$ & $195(133-245)$ & 2.8 \\
\hline Levetiracetam & - & $540 / 60$ & $540 / 60$ & 1389 (962-2041) & - \\
\hline Valproate & 239 (169-338) & $250 / 56$ & $400 / 89$ & 298 (201-418) & 1.2 \\
\hline Phenytoin & - & $>70 / 0$ & $70 / 0$ & $129(76-194)$ & - \\
\hline Carbamazepine & - & $56 / 89$ & $56 / 89$ & $36(27-48)$ & - \\
\hline Lamotrigine & - & $>56 / 33$ & $56 / 33$ & $20(13-27)$ & - \\
\hline Diazepam & - & 3/89 & 3/89 & $3(2-4)$ & - \\
\hline Topiramate & - & $>300 / 25$ & $300 / 25$ & 249 (150-357) & - \\
\hline Retigabine & - & $15 / 100$ & $15 / 100$ & $12(8-18)$ & - \\
\hline
\end{tabular}

MAD, minimally active dose, defined as the lowest dose providing statistically significant protection against focal to bilateral tonic-clonic seizures; MTD, maximal tested dose, defined as the highest dose tested in the amygdala kindling model; - , not calculated.

${ }^{a}$ Protection against focal to bilateral tonic-clonic seizures.

provided strong protection against pilocarpine-induced clonic seizures, where in contrast to the audiogenic model BRV is ineffective, while LEV shows relatively high potency. Among acute models, PSL displayed the highest potency in the $6 \mathrm{~Hz}$ model $\left(\mathrm{ED}_{50}\right.$ value of $\left.0.16 \mathrm{mg} / \mathrm{kg}\right)$, used as a test for protection against drug-resistant focal seizures, since many older (e.g., CBZ, phenobarbital, and PHT) and newer (e.g., felbamate, lamotrigine, tiagabine, and topiramate) AEDs fail to fully protect animals (Barton et al., 2001; (Detrait et al., 2008)). This model was also used to compare the efficacy of PSL against LEV, BRV, and DZP, and LEV/DZP and BRV/ DZP combinations. Importantly, for this comparison, doses
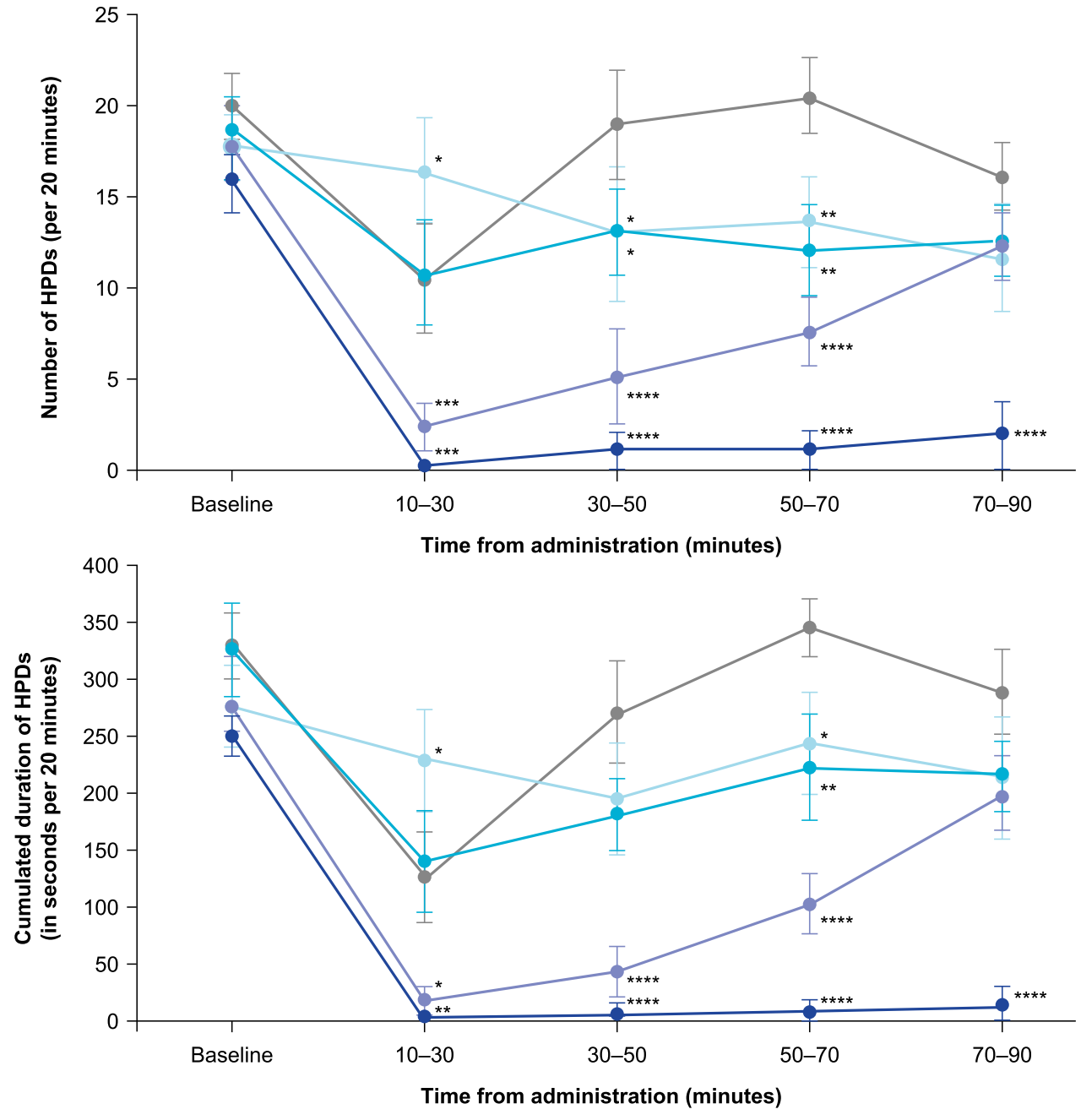

Fig. 3. PSL activity in the murine intrahippocampal kainate model: effect on the mean number (top panel) and the mean cumulated duration of HPDs (bottom panel). Values are mean \pm S.E.M. $(n=9)$; comparisons are $* P<0.05,{ }^{* *} P<$ $0.01, * * * P<0.001$, and $* * * * P<0.0001$ vs. baseline (Bonferroni's multiple comparisons test). 


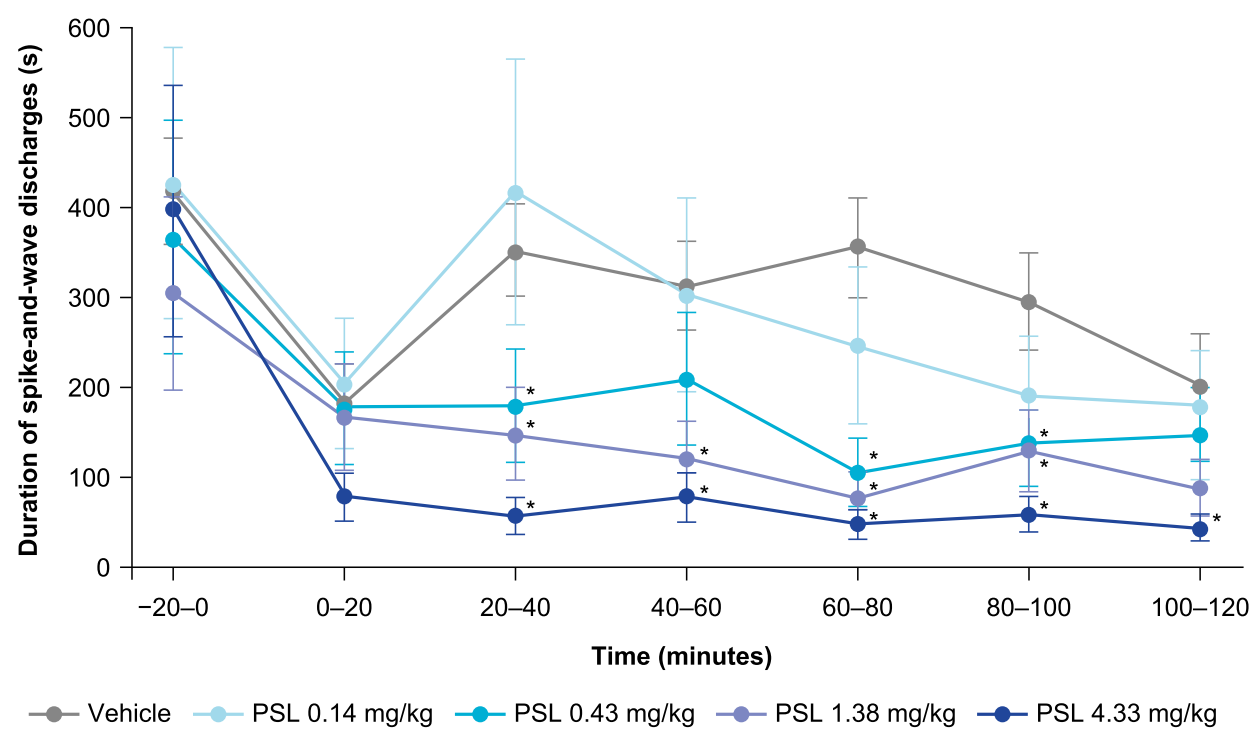

Fig. 4. PSL activity in the GAERS model: effect on the duration of spontaneous spikeand-wave discharges. Values are mean \pm S.E.M. ( $n=8$ per group), with $*$ indicating statistically significant differences with respective time points in vehicle-treated group $(P<0.05$; Bonferroni's multiple comparisons test).

calculated to provide similar SV2A and BZD site occupancy were used for the SV2 ligands and DZP, 35\% and 2\%, respectively. Given that $\mathrm{LEV}$ and $\mathrm{BRV}$ require $80 \% \mathrm{SV} 2 \mathrm{~A}$ for antiseizure activity in nonclinical models (Gillard et al., 2011) low-level occupancy was selected in these experiments to further differentiate PSL activity. Protection offered by PSL, even at 35\% SV2A occupancy was almost $70 \%$ and significantly greater than that provided by either LEV or BRV in combination with DZP. These observations suggest that PSL's antiseizure properties are due to a differentiated mode of action that provides greater protection than coadministration of an SV2A ligand and a BZD. Furthermore, the interaction of PSL with SV2B and SV2C may also contribute to enhanced antiseizure effects (Crèvecoeur et al., 2014).

The 11-deoxycortisol model is also considered to represent drug-resistant seizures (Kaminski et al., 2011). LEV offers only partial protection at the highest doses, while PHT, CBZ, and VPA are ineffective; BRV has also proven to be ineffective. However, PSL demonstrated robust efficacy, providing dose-dependent protection with an $\mathrm{ED}_{50}$ value of
$10 \mathrm{mg} / \mathrm{kg}$. 11-Deoxycortisol induces paroxysmal epileptiform network activity and seizures by significantly reducing GABAergic neurotransmission, which may explain why many AEDs, but not PSL, fail to suppress seizures (Kaminski et al., 2011).

The intrahippocampal kainate model displays many features of human mesial temporal lobe epilepsy (Riban et al., 2002; Pernot et al., 2011). Unilateral injection of kainate in the dorsal hippocampus results in neuronal loss, mossy fiber sprouting, and dispersion of granule cells, followed by spontaneous and recurrent HPDs observed on the EEG (Suzuki et al., 1995; Mitsuya et al., 2009). Focal seizures remain frequent and stable during the animal's life, and importantly, resistant to most AEDs (Riban et al., 2002, Duveau et al., 2016), as in human mesial temporal lobe epilepsy (Engel et al., 1997). PSL displayed dose-dependent protective effects, with almost complete and long-lasting inhibition of HPDs at the highest dose $(30 \mathrm{mg} / \mathrm{kg})$.

The GAERS model is considered predictive of human absence epilepsy (Danober et al., 1998; van Luijtelaar et al.,

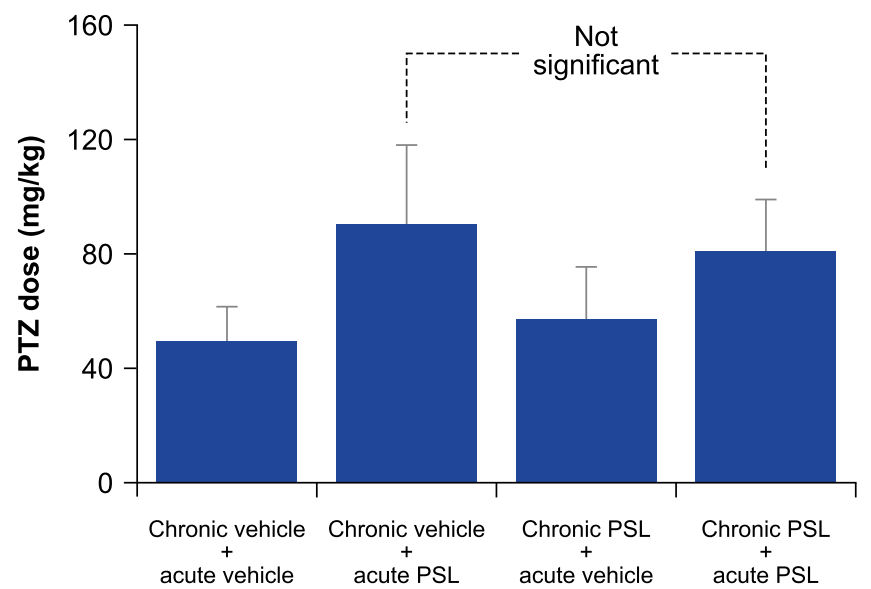

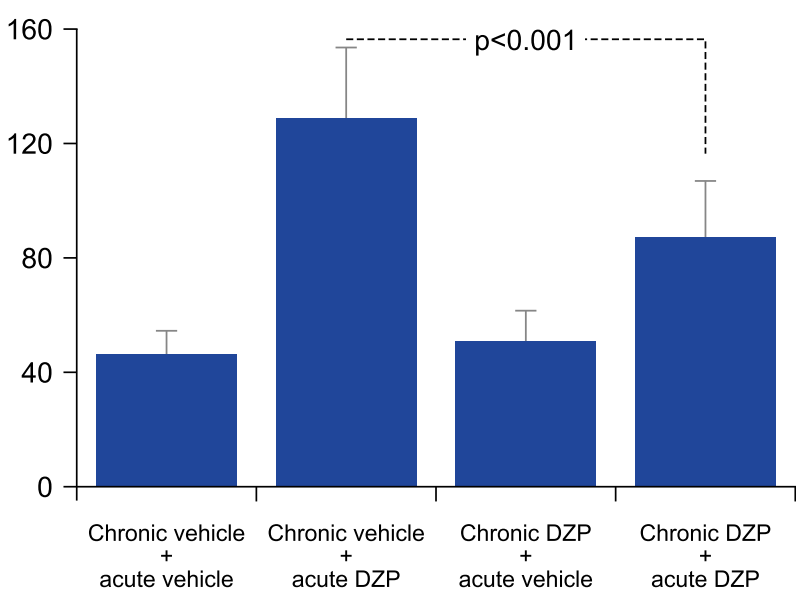

Fig. 5. Effect of chronic treatment (4 days) with PSL $(15.9 \mathrm{mg} / \mathrm{kg})$ or DZP $(2.1 \mathrm{mg} / \mathrm{kg})$ on the PTZ-induced seizure threshold. On the fifth day, PSL increased the threshold to the same extent in animals that had been treated chronically with vehicle or PSL. In contrast, there was a significant decrease in the ability of DZP to increase the threshold in animals that had been treated chronically with DZP, indicating development of tolerance. Development of tolerance was assessed based on statistically significant differences between chronic vehicle + test compound $\mathrm{ED}_{97}$ dose and chronic test compound $\mathrm{ED}_{97}$ dose + test compound $\mathrm{ED}_{97}$ dose using one-way ANOVA followed by Tukey's multiple comparisons test. 
2002). LEV has a weak effect in this model, while BRV suppresses spontaneous SWDs with complete inhibition at the highest dose $(67.9 \mathrm{mg} / \mathrm{kg})$, which again correlates with their affinity for SV2A (Kaminski et al., 2008; Matagne et al., 2008). PSL showed higher potency than BRV and markedly suppressed spontaneous SWDs with almost complete inhibition at the highest dose $(4.33 \mathrm{mg} / \mathrm{kg})$, providing further evidence for PSL's broad spectrum of activity against both focal and generalized seizures.

AED activity in the amygdala kindling model is predictive of efficacy against focal to bilateral tonic-clonic seizures in the clinical setting (Löscher and Schmidt, 1988). Electrographic and behavioral symptoms of seizures are initially localized at the site of stimulation, but rapidly evolve to bilateral activity, with seizures increasing in length and severity upon repeated stimulation (White, 2003; Löscher, 2011). In the rat model, PSL significantly reduced the proportion of animals displaying seizures, with $100 \%$ of animals protected at the highest dose. PSL also reduced the seizure severity score and the $\mathrm{ADD}$, indicating effects on both local seizure discharge and seizure spread, or evolution to bilateral seizures. PSL was substantially more potent than LEV and BRV; while BRV significantly reduces the ADD at only high doses, LEV has no effect (Klitgaard et al., 2016). PSL's effects in the mouse kindling model mirrored those in the rat model, with one exception: it reduced the ADD only at the highest dose. The reduction in $\mathrm{ADD}$ at the $13.9 \mathrm{mg} / \mathrm{kg}$ dose and the increase at the $1.38 \mathrm{mg} / \mathrm{kg}$ dose were both statistically significant, somewhat similar to the effects of low BRV doses (Matagne et al., 2008). In the mouse model, PSL was the most potent compared with nine other mechanistically different AEDs. It was only possible to determine the $\mathrm{ED}_{50}$ values of $\mathrm{BRV}$ and VPA since the others failed to provide full protection at high doses. The results were also used to compare the TI values of AEDs, a measure of the margin between antiseizure and adverse effects, expressed by the ratio between doses producing adverse effects and seizure protection $\left(\mathrm{TD}_{50} / \mathrm{ED}_{50}\right)$; the greater the TI, the greater is the separation between toxic and therapeutic doses. In mice, the PSL $\mathrm{TD}_{50}$ value was $12 \mathrm{mg} / \mathrm{kg}$ and the $\mathrm{ED}_{50}$ value was $1.2 \mathrm{mg} / \mathrm{kg}$, resulting in a $\mathrm{TI}$ of $10 . \mathrm{In}$ comparison, the TI values of BRV and VPA were 3 and 1 , respectively. Since the protective $\mathrm{ED}_{50}$ values of the remaining AEDs could not be determined, due to limited efficacy, their TI values could not be calculated. Overall, these findings indicate that PSL has full efficacy in the kindling model, displaying a high TI, potentially translating into higher efficacy and improved tolerability in humans.

PSL was designed to exert its therapeutic activity via two distinct mechanisms: as a SV2 ligand and as a partial agonist at the BZD site of the $\mathrm{GABA}_{\mathrm{A}} \mathrm{R}$. Partial agonism was selected based on evidence suggesting that the likelihood of developing tolerance to therapeutic effects is lower compared with full agonists (Miller et al., 1990; Serra et al., 1994; Löscher et al., 1996; Rundfeldt and Löscher, 2014). Clinical evidence supports these observations. Clobazam, a BZD and partial agonist, has been used successfully for the treatment of patients with Lennox-Gastaut syndrome (Faulkner, 2015; Gauthier and Mattson, 2015). The results of a long-term trial demonstrated sustained seizure control at stable dosages over a 3-year period (Conry et al., 2014; Gidal et al., 2016). Another partial agonist, abecarnil, has shown efficacy in the treatment of patients with photosensitive epilepsy without development of tolerance (Kasteleijn-Nolst Trenité et al., 2016). To evaluate PSL's tolerance potential, the PTZinduced clonic seizure threshold test was used, where the ability of AEDs to increase the seizure threshold is assessed after acute and twice daily administration for 4 days at the $\mathrm{ED}_{97}$ dose (Rundfeldt et al., 1995). Under both regimens, PSL increased the threshold for PTZ-induced seizures to the same extent, indicating that tolerance was not developed; in contrast, DZP showed significant loss in its ability to increase the threshold.

The precise role of SV2A in synaptic transmission and how ligand binding translates into antiseizure activity remain to be fully elucidated, yet the strength of ligands' antiseizure activity correlates with their binding affinity-BRV's greater affinity for SV2A over that of LEV translated into superior antiseizure activity in animal models (Kaminski et al., 2008; Matagne et al., 2008;(Löscher et al., 2016)). In turn, PSL's affinity for SV2A has been shown to be greater than that of BRV (Wood et al., 2019). PSL's additional actions on SV2B and $\mathrm{SV} 2 \mathrm{C}$, and the $\mathrm{GABA}_{\mathrm{A}} \mathrm{R}$ BZD site, have resulted in a nonclinical profile that differs substantially from that of other AEDs. Additional evidence from the present studies suggests that the pre- and postsynaptic mechanism of action confers enhanced antiseizure properties beyond the combination of compounds targeting SV2A and the BZD site. PSL's highly differentiated antiseizure profile suggests a robust therapeutic benefit, an observation supported by results of a phase IIb proof-of-concept trial (Muglia et al., 2017).

\section{Acknowledgments}

The authors thank Colette Chaussée, Fabienne Coddens, PierreYves Cortin, Michel Neveux, Muriel Petit, and Marie-Christine Tordeur (UCB Pharma, Braine L'Alleud, Belgium) for skillful technical assistance. They also thank Corinne Roucard and Alexis Evrard at Synapcell (Grenoble, France) for constructive discussions before, during, and after the murine mesial temporal lobe epilepsy study. The authors acknowledge Barbara Pelgrims (UCB Pharma, Brussels, Belgium) for overseeing the development of the manuscript, and Azita Tofighy for providing writing support, funded by UCB Pharma.

\section{Authorship Contributions}

Participated in research design: Leclercq, Matagne, Provins, Klitgaard, Kaminski.

Conducted experiments: Leclercq, Kaminski.

Contributed new reagents or analytic tools: Provins.

Performed data analysis: Leclercq, Kaminski.

Wrote or contributed to the writing of the manuscript: Leclercq, Klitgaard, Kaminski.

\section{References}

Barton ME, Klein BD, Wolf HH, and White HS (2001) Pharmacological characterization of the $6 \mathrm{~Hz}$ psychomotor seizure model of partial epilepsy. Epilepsy Res 47: 217-227.

Bialer M and White HS (2010) Key factors in the discovery and development of new antiepileptic drugs. Nat Rev Drug Discov 9:68-82.

Brodie MJ and Sills GJ (2011) Combining antiepileptic drugs-rational polytherapy? Seizure 20:369-375.

Chen Z, Brodie MJ, Liew D, and Kwan P (2018) Treatment outcomes in patients with newly diagnosed epilepsy treated with established and new antiepileptic drugs: a 30-year longitudinal cohort study. JAMA Neurol 75:279-286.

Conry JA, Ng Y-T, Kernitsky L, Mitchell WG, Veidemanis R, Drummond R, Isojarvi J, Lee D, and Paolicchi JM; OV-1004 Study Investigators (2014) Stable dosages of clobazam for Lennox-Gastaut syndrome are associated with sustained drop-seizure and total-seizure improvements over 3 years. Epilepsia 55:558-567.

Crèvecoeur J, Kaminski RM, Rogister B, Foerch P, Vandenplas C, Neveux M, Mazzuferi M, Kroonen J, Poulet C, Martin D, et al. (2014) Expression pattern of synaptic vesicle protein 2 (SV2) isoforms in patients with temporal lobe epilepsy and hippocampal sclerosis. Neuropathol Appl Neurobiol 40:191-204.

Danober L, Deransart C, Depaulis A, Vergnes M, and Marescaux C (1998) Pathophysiological mechanisms of genetic absence epilepsy in the rat. Prog Neurobiol 55: $27-57$. 
Detrait E, Leclercq K, Matagne A, and Klitgaard H (2008) Protective activity of brivaracetam in the $6 \mathrm{~Hz}$ model of partial epilepsy: comparison with levetiracetam and older antiepileptic drugs (Abstract). Epilepsia 49 (Suppl 7):1.252.

Devinsky O, Vezzani A, O’Brien TJ, Jette N, Scheffer IE, de Curtis M, and Perucca P (2018) Epilepsy. Nat Rev Dis Primers 4:18024.

Duveau V, Pouyatos B, Bressand K, Bouyssières C, Chabrol T, Roche Y, Depaulis A and Roucard C (2016) Differential effects of antiepileptic drugs on focal seizures in the intrahippocampal kainate mouse model of mesial temporal lobe epilepsy. CNS Neurosci Ther 22:497-506.

Engel JJ, Williamson PD, and Wieser HG (1997) Mesial temporal lobe epilepsy, in A Comprehensive Textbook (Engel J and Pedley TA eds), Raven Press, Philadelphia.

Faulkner MA (2015) Comprehensive overview: efficacy, tolerability, and costeffectiveness of clobazam in Lennox-Gastaut syndrome. Ther Clin Risk Manag 11:905-914.

French JA and Faught E (2009) Rational polytherapy. Epilepsia 50 (Suppl 8):63-68

Gauthier AC and Mattson RH (2015) Clobazam: a safe, efficacious, and newly rediscovered therapeutic for epilepsy. CNS Neurosci Ther 21:543-548.

Gidal BE, Wechsler RT, Sankar R, Montouris GD, White HS, Cloyd JC, Kane MC, Peng G, Tworek DM, Shen V, et al. (2016) Deconstructing tolerance with clobazam: post hoc analyses from an open-label extension study. Neurology 87:1806-1812.

Gillard M, Fuks B, Leclercq K, and Matagne A (2011) Binding characteristics of brivaracetam, a selective, high affinity SV2A ligand in rat, mouse and human brain: relationship to anti-convulsant properties. Eur J Pharmacol 664:36-44.

Jackson HC, Hansen HC, Kristiansen M, Suzdak PD, Klitgaard H, Judge ME and Swedberg MD (1996) Anticonvulsant profile of the imidazoquinazolines NNC 14-0185 and NNC 14-0189 in rats and mice. Eur $J$ Pharmacol 308:21-30.

Kalilani L, Sun X, Pelgrims B, Noack-Rink M, and Villanueva V (2018) The epidemiology of drug-resistant epilepsy: a systematic review and meta-analysis. Epilepsia 59:2179-2193.

Kaminski R, Fu Z, Venkatesan K, Mazzuferi M, Leclercq K, Seutin V, and Vicini S (2011) 11-Deoxycortisol impedes GABAergic neurotransmission and induces drugresistant status epilepticus in mice. Neuropharmacology 60:1098-1108.

Kaminski RM, Matagne A, Leclercq K, Gillard M, Michel P, Kenda B, Talaga P, and Klitgaard H (2008) SV2A protein is a broad-spectrum anticonvulsant target: functional correlation between protein binding and seizure protection in models of both partial and generalized epilepsy. Neuropharmacology 54:715-720.

Kaminski RM, Matagne A, Patsalos PN, and Klitgaard H (2009) Benefit of combination therapy in epilepsy: a review of the preclinical evidence with levetiracetam. Epilepsia 50:387-397.

Kasteleijn-Nolst Trenité DG, Groenwold RH, Schmidt B, and Löscher W (2016) Single dose efficacy evaluation of two partial benzodiazepine receptor agonists in photosensitive epilepsy patients: a placebo-controlled pilot study. Epilepsy Res 122: $30-36$.

Klitgaard H (2005) Antiepileptic drug discovery: lessons from the past and future challenges. Acta Neurol Scand Suppl 181 (Suppl 181):68-72.

Klitgaard H, Matagne A, Gobert J, and Wülfert E (1998) Evidence for a unique profile of levetiracetam in rodent models of seizures and epilepsy. Eur $J$ Pharmacol 353 191-206.

Klitgaard H, Matagne A, Nicolas J-M, Gillard M, Lamberty Y, De Ryck M, Kaminski RM, Leclercq K, Niespodziany I, Wolff C, et al. (2016) Brivaracetam: rationale for discovery and preclinical profile of a selective SV2A ligand for epilepsy treatment. Epilepsia 57:538-548.

Klitgaard H and Verdru P (2007) Levetiracetam: the first SV2A ligand for the treatment of epilepsy. Expert Opin Drug Discov 2:1537-1545.

Kwan P, Arzimanoglou A, Berg AT, Brodie MJ, Allen Hauser W, Mathern G, Moshé SL, Perucca E, Wiebe S, and French J (2010) Definition of drug resistant epilepsy: consensus proposal by the ad hoc Task Force of the ILAE Commission on Therapeutic Strategies. Epilepsia 51:1069-1077.

Leclercq K and Kaminski RM (2015) Genetic background of mice strongly influences treatment resistance in the $6 \mathrm{~Hz}$ seizure model. Epilepsia 56:310-318.

Löscher W (2011) Critical review of current animal models of seizures and epilepsy used in the discovery and development of new antiepileptic drugs. Seizure 20: 359-368.

Löscher W, Gillard M, Sands ZA, Kaminski RM, and Klitgaard H (2016) Synaptic vesicle glycoprotein $2 \mathrm{~A}$ ligands in the treatment of epilepsy and beyond. CNS Drugs 30:1055-1077.

Löscher W, Jäckel R, and Czuczwar SJ (1986) Is amygdala kindling in rats a model for drug-resistant partial epilepsy? Exp Neurol 93:211-226.

Löscher W, Klitgaard H, Twyman RE, and Schmidt D (2013) New avenues for antiepileptic drug discovery and development. Nat Rev Drug Discov 12:757-776.

Löscher W, Rundfeldt C, Hönack D, and Ebert U (1996) Long-term studies on anticonvulsant tolerance and withdrawal characteristics of benzodiazepine receptor ligands in different seizure models in mice. I. Comparison of diazepam, clonazepam, clobazam and abecarnil. $J$ Pharmacol Exp Ther 279:561-572.

Löscher W and Schmidt D (1988) Which animal models should be used in the search for new antiepileptic drugs? A proposal based on experimental and clinical considerations. Epilepsy Res 2:145-181.

Lynch BA, Lambeng N, Nocka K, Kensel-Hammes P, Bajjalieh SM, Matagne A, and Fuks B (2004) The synaptic vesicle protein SV2A is the binding site for the antiepileptic drug levetiracetam. Proc Natl Acad Sci USA 101:9861-9866.

Matagne A, Margineanu DG, Kenda B, Michel P, and Klitgaard H (2008) Anticonvulsive and anti-epileptic properties of brivaracetam (ucb 34714), a highaffinity ligand for the synaptic vesicle protein, SV2A. $\mathrm{Br} J$ Pharmacol 154: $1662-1671$.

Matagne A, Margineanu DG, Potschka H, Löscher W, Michel P, Kenda B, and Klitgaard $\mathrm{H}$ (2009) Profile of the new pyrrolidone derivative seletracetam (ucb 44212) in animal models of epilepsy. Eur J Pharmacol 614:30-37.

Miller LG, Galpern WR, Greenblatt DJ, Lumpkin M, and Shader RI (1990) Chronic benzodiazepine administration. VI. A partial agonist produces behavioral effects without tolerance or receptor alterations. J Pharmacol Exp Ther 254:33-38.

Mitsuya K, Nitta N, and Suzuki F (2009) Persistent zinc depletion in the mossy fiber terminals in the intrahippocampal kainate mouse model of mesial temporal lobe epilepsy. Epilepsia 50:1979-1990.

Muglia P, Toledo M, Steinhoff BJ, Majoie M, Webster E, Otoul C, De Bruyn S, Van Paesschen W, Boon P, and Werhahn KJ (2017) Efficacy and tolerability of adjunctive padsevonil in adults with drug-resistant focal onset seizures: a randomized, double-blind, placebo-controlled, proof-of-concept trial. American Epilepsy Society (AES) Annual Meeting Abstract Database. AESnet.org.

Pernot F, Heinrich C, Barbier L, Peinnequin A, Carpentier P, Dhote F, Baille V, Beaup C, Depaulis A, and Dorandeu F (2011) Inflammatory changes during epileptogenesis and spontaneous seizures in a mouse model of mesiotemporal lobe epilepsy. Epilepsia 52:2315-2325

Racine RJ (1972) Modification of seizure activity by electrical stimulation. II. Motor seizure. Electroencephalogr Clin Neurophysiol 32:281-294.

Riban V, Bouilleret V, Pham-Lê BT, Fritschy JM, Marescaux C, and Depaulis A (2002) Evolution of hippocampal epileptic activity during the development of hippocampal sclerosis in a mouse model of temporal lobe epilepsy. Neuroscience 112:101-111.

Rundfeldt C and Löscher W (2014) The pharmacology of imepitoin: the first partial benzodiazepine receptor agonist developed for the treatment of epilepsy. CNS Drugs 28:29-43.

Rundfeldt C, Wlaź P, Hönack D, and Löscher W (1995) Anticonvulsant tolerance and withdrawal characteristics of benzodiazepine receptor ligands in different seizure models in mice. Comparison of diazepam, bretazenil and abecarnil. J Pharmacol Exp Ther 275:693-702.

Serra M, Ghiani CA, Motzo C, Porceddu ML, and Biggio G (1994) Long-term treatment with abecarnil fails to induce tolerance in mice. Eur $J$ Pharmacol 259:1-6.

Suzuki F, Junier MP, Guilhem D, Sørensen JC, and Onteniente B (1995) Morphogenetic effect of kainate on adult hippocampal neurons associated with a prolonged expression of brain-derived neurotrophic factor. Neuroscience 64:665-674.

Thijs RD, Surges R, O'Brien TJ, and Sander JW (2019) Epilepsy in adults. Lancet 393:689-701.

Trinka E (2012) Ideal characteristics of an antiepileptic drug: how do these impact treatment decisions for individual patients? Acta Neurol Scand Suppl 194:10-18.

Turski L, Stephens DN, Jensen LH, Petersen EN, Meldrum BS, Patel S, Hansen JB, Löscher W, Schneider HH, and Schmiechen R (1990) Anticonvulsant action of the beta-carboline abecarnil: studies in rodents and baboon, Papio papio. J Pharmacol Exp Ther 253:344-352.

van Luijtelaar EL, Drinkenburg WH, van Rijn CM, and Coenen AM (2002) Rat models of genetic absence epilepsy: what do EEG spike-wave discharges tell us about drug effects? Methods Find Exp Clin Pharmacol 24 (Suppl D):65-70.

White HS (2003) Preclinical development of antiepileptic drugs: past, present, and future directions. Epilepsia 44 (Suppl 7):2-8.

Wolff C, Mullier B, Ghisdal P, Provins L, and Kaminski RM (2017) Functional characterization of padsevonil on GABA-A receptors. American Epilepsy Society (AES) Annual Meeting Abstract Database. AESnet.org.

Wood M, Daniels V, Provins L, Wolff C, Kaminski RM, and Gillard M (2019) Pharmacological profile of the antiepileptic drug candidate padsevonil-interactions with synaptic vesicle 2 proteins and $\mathrm{GABA}_{\mathrm{A}}$ receptors. J Pharmacol Exp Ther in press.

Address correspondence to: Karine Leclercq, UCB Pharma, Chemin du Foriest, 1420 Braine l'Alleud, Belgium. E-mail: Karine.Leclercq@ucb.com 